\title{
Binocular rivalry between single lines viewed as real images and afterimages
}

\author{
N. J. WADE \\ University of Dundee, Dundee DD1 $4 \mathrm{HN}$, Scotland
}

\begin{abstract}
Binocular rivalry alternations between single lines oriented at 0 and $90 \mathrm{deg}$ or 0 and 45 deg were measured. The lines were viewed as either real images or afterimages. The experiment was designed to determine whether or not a vertical $(0 \mathrm{deg})$ line predominates for longer than a nonvertical line and to compare the temporal characteristics of rivalry between real images and afterimages. There were no systematic differences in predominance durations under any of the rivalry pairings or viewing conditions. The dominance periods for rivalry between afterimages were longer than those for real images. Frequency distributions of the dominance periods were all positively skewed, and the parameters of the fitted gamma distributions were similar in all cases. Tests of the sequential dependence of successive dominance periods indicated that they were independent for both real images and afterimages.
\end{abstract}

The temporal characteristics of binocular rivalry between alterimages differ from those for real images: the phases or periods for which one monocular stimulus remains doninant are longer for afterimages than for real images (Breese, 1899; Wade, 1974). For rivalry between differently oriented gratings, the average dominance periods were in the order of $4 \mathrm{sec}$ for afterimages but between 1 and $2 \mathrm{sec}$ for real images (Wade, 1974). Wade suggested that the shorter dominance periods with real images were related to the involuntary eye movements that would occur during such observation. More specifically, the displacement of a contour on one or both eyes as a consequence of eye movement could terminate the ongoing phase of suppression, and a new one would be initiated. With afterimages, the involuntary eye movements do not result in any contour displacements, and so the time course of rivalry can be considered to represent the operation of the central mechanism involved in rivalry. Accordingly, an analysis of the temporal sequence of rivalry durations for afterimages and real images might provide evidence of their dependence or independence. It is plausible to argue that rivalry durations are systematically related for afterimages, reflecting the central inhibitory interactions, but are independent for real images due to the effects of involuntary eye movements. This line of enquiry has been pursued for ring-disk rivalry by Blake, Fox, and McIntyre (1971), using afterimages, and by Fox and Herrmann (1967), using real images. They examined the stochastic properties of rivalry alternations using a runs test, autocorrelation. and by an analysis of the frequency distributions. The results for both real images and

This research was supported by a grant from the Science Research Council. The assistance of Kirsteen Greig in the collection and analysis of the data is gratefully acknowledged. afterimages indicated that successive rivalry durations were independent.

For rivalry between gratings, Wade (1974) found that the frequency distributions for both real images and afterimages were positively skewed, and that they conformed to the general shape of the gamma distribution. However, rivalry between gratings is not characterized by alternations alone; composites, in which different orientations dominate in different parts of the field, are also evident. This prevented further stochastic analyses of the types conducted with ring-disk rivalry. Since it does seem important to establish whether the same conclusions apply to contour rivalry alternations, an experiment was conducted using single lines viewed as real images and as afterimages. Single lines undergo rivalry only at or around their regions of overlap. Often one line can be seen in its entirety while the extremities of the other line remain visible. Other fragments are also visible on occasion, including the visibility of both lines in their entirety (Cogan \& Goldstein, 1972). In the experiment to be reported, a line was defined as dominant if its contours appeared unbroken. In order to increase the likelihood of suppression spreading over the whole of one line, so that a single line was visible, short lines subtending $1 \times 1 / 4 \mathrm{deg}$ were employed.

An additional feature of the experiment was to determine whether or not the pattern of rivalry between single lines is influenced by their orientation. Single-line afterimages viewed monocularly do not show differences in the duration of visibility with variation in orientation (Wade, 1972), whereas grating afterimages do (Wade, 1973): vertical gratings remain visible in unitary form for longer than do those at $45 \mathrm{deg}$. Similar orientation selectivity has been demonstrated during binocular rivalry between grating afterimages (Wade, 1974). It is of interest to 
determine whether single-line afterimages of 0 and $45 \mathrm{deg}$ evidence orientation selectivity during binocular rivalry. Accordingly, a 0 - vs. 45-deg configuration was studied in addition to a 0 - vs. 90-deg pairing.

The experiment was, therefore, concerned with two problems. One, whether or not the predominance of single lines in rivalry varies with orientation; and the other, whether or not the stochastic properties of dominance periods vary for rivalry between real images and afterimages. In order to obtain sufficient data for the stochastic analysis, a small number of subjects was tested intensively.

\section{APPARATUS AND PROCEDURE}

The apparatus was essentially similar to that used in the previous study (Wade, 1974). The rivalrous stimuli were viewed in a prism stereoscope. They were formed from apertures in black masking card. and each line subtended $1 \times 1 / 4$ deg at the eye. The lines could be adjusted by means of biprisms to intersect at their centers. The orientations of the rivalrous lines were 0 and $90 \mathrm{deg}$ or 0 and $45 \mathrm{deg}$. Binocular alignment of the real images was maintained by two narrow annuli (3-deg diam) surrounding the lines. The luminance of the apertures in the real-image condition was $1 \mathrm{fL}$. Afterimages were generated by the discharge of a Multiblitz Report flash gun, with an output of $120 \mathrm{~J}$ in $2 \mathrm{msec}$. The fusion annuli were dispensed with in this condition, and a dim light illuminated the apertures prior to the flash, to allow binocular alignment. Two suitches were positioned in front of the subject: these activated timers and separate channels of a Rustrak event recorder. which enabled measurement of durations to $.1 \mathrm{sec}$.

Four subjects were tested, two of whom had participated in the previous study (Wade, 1974). None had any evidence of astigmatism, as determined by Lancaster-Regan type astigmatic dials presented in a Keystone telebinocular.

Each subject was tested in eight sessions for afterimages and eight for real images. The task involved pressing the right-hand switch for the duration of dominance of the vertical line and the left-hand switch for the nonvertical ( 45 or $90 \mathrm{deg}$ ) line. A line was defined as dominant if its contours appeared unbroken. A session consisted of eight 1 -min rivalry trials. The rivalrous configurations were balanced over eyes to control for eye-dominance effects, and each condition was tested twice within a session.

For the afterimage condition, the subject was initially dark adapted for $10 \mathrm{~min}$. A dim light illuminated the apertures to enable binocular alignment, whereupon the subject activated the flash discharge. The rivalrous afterimages were observed with the eyes closed for 2 min. Only the first minute of which was used in the analysis. The intertrial interval was $3 \mathrm{~min}$. during which the subject was dark adapted.

Binocular alignment of the real images was maintained by means of the surrounding annuli, and the subject responded in terms of the dominance of either line for the 1-min observation period.

\section{RESULTS AND DISCUSSION}

All subjects reported that rivalry between afterimages was easier to follow than that between real images: dominance was associated much more often with the visibility of one line alone. That is, suppression spread over the whole of one line much more frequently for afterimages, whereas rivalry was contined mainly to the area of intersection of the real images, with the ends of both lines remaining visible. Occasionally, in the real image condition, the subjects reported seeing all the contours of both lines fleetingly (see Cogan. 1973; Cogan \& Goldstein, 1972).

Examination of the event recordings suggested that the alternation rate for afterimages was higher in the initial stages of observation than towards the end of the inspection period. In order to investigate this systematically, the inspection period was divided into the first and second 30 -sec intervals. The division was no exact inasmuch as it was measured to the nearest response alternation, as was the termination of the trial at the end of $60 \mathrm{sec}$.

The predominance durations are given in Table 1 for all the rivalry conditions. For the afterimage condition, the observation period was timed from the discharge of the flash gun. There followed a short interval before one of the line afterimages became visible. This interval was consistent for a given subject and did not differ over configurations; its mean value was $3.1 \mathrm{sec}$, and this duration would need to be added to durations given in Table 1 for the first $30 \mathrm{sec}$ in order to indicate that there was only, on average, about 1 sec during which neither line was visible.

The data for real images and afterimages were analyzed separately. Analyses of variance were

Table 1

Mean Predominance Durations (Seconds) for Each Subject Under All Rivalry Conditions

\begin{tabular}{|c|c|c|c|c|c|c|c|c|c|c|c|c|c|c|c|c|c|}
\hline \multirow{2}{*}{\multicolumn{2}{|c|}{$\begin{array}{l}\text { Rivalry } \\
\text { Configuration }\end{array}$}} & \multicolumn{8}{|c|}{ Real Images } & \multicolumn{8}{|c|}{ Af terimages } \\
\hline & & $\begin{array}{c}\text { LE } \\
0\end{array}$ & s. $\begin{array}{l}\text { RE } \\
90\end{array}$ & $\begin{array}{c}\mathbf{R E} \\
0\end{array}$ & vs. $\begin{array}{l}\text { LE } \\
90\end{array}$ & $\underset{0}{\mathrm{LE}} \mathrm{v}$ & $\begin{array}{l}\text { RE } \\
45\end{array}$ & $\underset{0}{\mathrm{RE}} \mathrm{v}$ & s. LE & $\underset{0}{\text { LE }} \mathrm{v}$ & $\begin{array}{l}\text { RE } \\
90\end{array}$ & $\underset{0}{\mathrm{RE}} \mathrm{v}$ & vs. $\begin{array}{l}\text { LE } \\
90\end{array}$ & $\begin{array}{c}\mathrm{LE} \\
0\end{array}$ & vs. $\begin{array}{l}\text { RE } \\
45\end{array}$ & $\underset{0}{\mathrm{RE}} \mathrm{v}$ & s. LE \\
\hline \multicolumn{2}{|c|}{$\begin{array}{l}\text { Orientation } \\
\text { Visible } \\
\end{array}$} & 0 & 90 & 0 & 90 & 0 & 45 & 0 & 45 & 0 & 90 & 0 & 90 & 0 & 45 & 0 & 45 \\
\hline $\begin{array}{l}\text { First } \\
30 \mathrm{Sec}\end{array}$ & $\begin{array}{l}\text { S1 } \\
\text { S2 } \\
\text { S3 } \\
\text { S4 } \\
\text { M }\end{array}$ & $\begin{array}{r}22.6 \\
15.9 \\
20.3 \\
9.7 \\
17.1\end{array}$ & $\begin{array}{r}6.9 \\
14.1 \\
10.7 \\
18.5 \\
12.6\end{array}$ & $\begin{array}{r}9.4 \\
16.6 \\
14.9 \\
20.1 \\
15.3\end{array}$ & $\begin{array}{l}20.0 \\
13.0 \\
14.5 \\
10.2 \\
14.4\end{array}$ & $\begin{array}{r}23.8 \\
14.9 \\
16.5 \\
8.7 \\
16.0\end{array}$ & $\begin{array}{r}5.6 \\
14.7 \\
13.2 \\
21.9 \\
13.8\end{array}$ & $\begin{array}{r}5.7 \\
14.8 \\
13.3 \\
19.6 \\
13.4\end{array}$ & $\begin{array}{l}23.5 \\
14.7 \\
15.9 \\
11.1 \\
16.3\end{array}$ & $\begin{array}{l}11.4 \\
14.0 \\
13.9 \\
11.5 \\
12.7\end{array}$ & $\begin{array}{l}14.2 \\
14.7 \\
14.0 \\
11.0 \\
13.5\end{array}$ & $\begin{array}{l}13.0 \\
13.6 \\
14.4 \\
12.8 \\
13.4\end{array}$ & $\begin{array}{l}13.0 \\
14.4 \\
14.1 \\
10.2 \\
12.9\end{array}$ & $\begin{array}{l}10.7 \\
13.8 \\
14.4 \\
10.9 \\
12.4\end{array}$ & $\begin{array}{l}12.1 \\
14.7 \\
13.4 \\
11.7 \\
13.0\end{array}$ & $\begin{array}{l}11.4 \\
13.6 \\
14.7 \\
14.0 \\
13.4\end{array}$ & $\begin{array}{r}14.2 \\
13.7 \\
13.6 \\
9.7 \\
12.8\end{array}$ \\
\hline $\begin{array}{l}\text { Second } \\
30 \mathrm{Sec}\end{array}$ & $\begin{array}{l}\text { S1 } \\
\text { S2 } \\
\text { S3 } \\
\text { S4 } \\
\text { M }\end{array}$ & $\begin{array}{l}23.5 \\
15.0 \\
18.7 \\
11.9 \\
17.3\end{array}$ & $\begin{array}{r}6.6 \\
14.5 \\
10.6 \\
19.6 \\
12.8\end{array}$ & $\begin{array}{l}10.5 \\
15.8 \\
17.3 \\
17.2 \\
15.2\end{array}$ & $\begin{array}{l}19.4 \\
13.8 \\
12.5 \\
12.2 \\
14.5\end{array}$ & $\begin{array}{r}25.7 \\
14.2 \\
14.3 \\
9.3 \\
15.9\end{array}$ & $\begin{array}{r}4.6 \\
15.1 \\
16.0 \\
19.8 \\
13.9\end{array}$ & $\begin{array}{r}5.3 \\
14.6 \\
15.0 \\
15.9 \\
12.7\end{array}$ & $\begin{array}{l}25.0 \\
15.1 \\
15.5 \\
12.8 \\
17.1\end{array}$ & $\begin{array}{l}12.2 \\
14.1 \\
15.4 \\
13.4 \\
13.8\end{array}$ & $\begin{array}{l}11.9 \\
14.6 \\
14.2 \\
14.7 \\
13.8\end{array}$ & $\begin{array}{l}10.8 \\
16.3 \\
12.2 \\
15.5 \\
13.7\end{array}$ & $\begin{array}{l}14.0 \\
14.6 \\
16.5 \\
12.6 \\
14.4\end{array}$ & $\begin{array}{l}11.6 \\
15.6 \\
16.5 \\
16.2 \\
14.9\end{array}$ & $\begin{array}{l}11.9 \\
14.1 \\
13.8 \\
11.8 \\
12.9\end{array}$ & $\begin{array}{l}10.5 \\
14.5 \\
14.0 \\
17.4 \\
14.1\end{array}$ & $\begin{array}{l}14.2 \\
16.4 \\
15.4 \\
11.1 \\
14.3\end{array}$ \\
\hline
\end{tabular}


Table 2

Mean Durations (Seconds) of Dominance Periods for Each Subject Under All Rivalry Conditions

\begin{tabular}{|c|c|c|c|c|c|c|c|c|c|c|c|c|c|c|c|c|c|}
\hline & & \multicolumn{8}{|c|}{ Real Images } & \multicolumn{8}{|c|}{ Afterimages } \\
\hline \multirow{2}{*}{\multicolumn{2}{|c|}{$\begin{array}{l}\text { Rivalry } \\
\text { Configuration }\end{array}$}} & LE & s. ${ }^{R E}$ & $\mathrm{RE}_{\mathrm{v}}$ & LE & $L E_{\text {vs }}$ & $\mathrm{RE}$ & $R E_{v s}$ & LE & $\mathrm{LE}_{\mathrm{v}}$ & $\mathrm{RE}$ & $R E_{v}$ & LE & $\mathrm{LE}_{v}$ & RE & $R E_{\text {vs }}$ & s. ${ }^{\text {LE }}$ \\
\hline & & & 90 & 0 & 90 & 0 & 45 & 0 & 45 & 0 & 90 & 0 & 90 & 0 & 45 & 0 & 45 \\
\hline \multicolumn{2}{|c|}{$\begin{array}{l}\text { Orientation } \\
\text { Visible }\end{array}$} & 0 & 90 & 0 & 90 & 0 & 45 & 0 & 45 & 0 & 90 & 0 & 90 & 0 & 45 & 0 & 45 \\
\hline \multirow{5}{*}{$\begin{array}{l}\text { First } \\
30 \mathrm{Sec}\end{array}$} & $\mathrm{S} 1$ & 3.4 & 1.1 & 1.1 & 2.2 & 4.5 & 1.2 & 1.0 & 3.8 & 3.5 & 4.2 & 3.9 & 3.4 & 3.4 & 3.5 & 3.1 & 3.6 \\
\hline & S2 & 1.4 & 1.3 & 1.5 & 1.2 & 1.3 & 1.3 & 1.2 & 1.2 & 4.2 & 4.3 & 3.8 & 4.4 & 4.9 & 5.0 & 3.8 & 4.4 \\
\hline & S3 & 4.0 & 2.2 & 3.0 & 2.8 & 3.3 & 2.7 & 2.8 & 3.2 & 4.4 & 4.1 & 3.1 & 3.2 & 4.2 & 3.6 & 3.4 & 3.4 \\
\hline & S4 & 6.0 & 9.2 & 8.2 & 4.8 & 4.0 & 8.4 & 7.5 & 4.9 & 5.4 & 4.9 & 5.4 & 4.2 & 4.4 & 4.7 & 5.0 & 4.0 \\
\hline & M & 3.7 & 3.5 & 3.5 & 2.8 & 3.3 & 3.4 & 3.1 & 3.3 & 4.4 & 4.4 & 4.1 & 3.8 & 4.2 & 4.2 & 3.8 & 3.9 \\
\hline \multirow{5}{*}{$\begin{array}{l}\text { Second } \\
30 \mathrm{Sec}\end{array}$} & S1 & 3.7 & 1.1 & 1.3 & 2.4 & 4.9 & 1.0 & .9 & 4.2 & 4.1 & 4.0 & 3.7 & 4.7 & 5.1 & 5.0 & 4.4 & 5.1 \\
\hline & S2 & 1.4 & 1.4 & 1.5 & 1.3 & 1.3 & 1.4 & 1.3 & 1.3 & 5.5 & 5.6 & 5.2 & 5.0 & 8.6 & & 7.0 & 7.1 \\
\hline & S3 & 4.0 & 2.4 & 4.1 & 3.0 & 2.8 & 3.0 & 3.2 & 3.5 & 8.5 & 7.8 & 6.7 & 8.0 & 7.7 & 6. & 7.7 & 7.5 \\
\hline & S4 & 7.6 & 10.8 & 9.8 & 7.2 & 3.6 & 7.2 & 6.1 & 4.8 & 6.9 & 6.7 & 7.7 & 6.3 & 7.2 & 5.7 & 9.0 & 5.9 \\
\hline & M & 4.2 & 3.9 & 4.2 & 3.5 & 3.2 & 3.2 & 2.9 & 3.4 & 6.2 & 6.0 & 5.8 & 6.0 & 7.2 & 6.5 & 7.0 & 6.4 \\
\hline
\end{tabular}

performed on the averaged data for each subject given in Table 1. Each analysis involved 16 levels (eight predominance measures for the first and second 30-sec intervals), and subsequent post hoc comparisons between means were carried out using the method devised by Rodger (1965). For the afterimage rivalry conditions, no significant differences were found $[F(15.45)=0.88, p>.05]$. That is, there were no significant differences either between the orientations used or between the first and second $30 \mathrm{sec}$ of observation. More specifically, a vertical-line afterimage was visible for approximately the same duration as a 90-deg or a 45-deg line in rivalry with it. These results are in agreement with those for single-line afterimages viewed monocularly (Wade. 1972), in that no differences in the durations of visibility were found for different orientations.

Rivalry between real images did not differ significantly in terms of the predominance measures $[F(15,45)=0.34, p>.05]$. Durations for the 0 - and 45-deg lines were very similar. There was a small, but nonsigniticant, effect in the $0-$ vs. $90-\mathrm{deg}$ pairings, with the vertical line being visible for longer than the horizontal. This may have been due to some slight horizontal nonconjugate movements of the eyes that probably took place in spite of the fusion annuli (Kaufman, 1963). Such horizontal movements of one eye relative to the other would have favored the visibility of the vertical line, as it would have been displaced onto a new retinal area, whereas only the ends of the horizontal lines would be so displaced.

An unexpected feature of the data concerned the differential effects of eye dominance (as determined by the duration of visibility of the target presented to onc eye relative to the other), under the two viewing comditions. In general, Subjects 2 and 3 showed relatively litlle eye dominance, whereas it was more pronounced for Subjects 1 and 4 (see Table 1). For all subjects, eye-dominance effects were smaller in the aflerimatge lhan in the real-image condition: the ratio wh the left to the right eye predominance durations for
Subjects 1.4 were $1.08,1.01,1.08$, and 0.88 for afterimages and $3.34,0.97,1.15$, and 0.56 for real images. Although caution is necessary when interpreting the effects from such a small sample, the following points do seem worthy of note. Examination of the data for real images of Subjects 1, 3, and 4, who showed some eye dominance with real images, suggests that the eye-dominance effects interacted with the contour orientation. Presentation of a vertical line to the dominant eye resulted in longer predominance durations than did presentation of a nonvertical line to that eye. Since this effect was not evident in the afterimage data, it is likely to be a function of the small eye movements that do occur under normal stereoscopic viewing conditions. It is possible to speculate upon the basis of this interaction between eye dominance and orientation. First, the data from afterimage rivalry, in which eye dominance effects are reduced, would imply that the suppression involved in rivalry is fairly equal for the two eyes. That is, if it is assumed that rivalry between afterimages reflects the interocular suppression in a manner uncontaminated by contour displacements, then this suppression operates almost equally. Second, small eye movements occur more frequently in the horizontal than in the vertical plane with differential consequences for the rivalrous contours as outlined above. Either the effect of the moving vertical contour in the dominant eye leads to suppression of the nondominant eye or suppression builds up more rapidly in the dominant eye when a new area is stimulated.

Another factor which suggests that rivalry between afterimages retlects more precisely the characteristics of the suppression process concerns the dominance periods under the two conditions. The average durations of the dominance periods were determined by dividing the predominance durations by the frequencies of visibility, and these values are shown in Table 2 for all conditions. The dominance periods were longer during rivalry between afterimages than 
between real images. This pattern of results could be produced if the normally long periods of interocular suppression were interrupted by contour displacements on the retina, such that a new state of suppression was initiated. A similar result was reported for rivalry between gratings (Wade, 1974), although the differences are not so marked for single lines. While the difference is clear for Subjects 1-3, Subject 4 shows the reverse effect, with the dominance periods for real images exceeding those for afterimages. The variation between subjects is considerably greater for real images than for afterimages. The overall dominance durations were around $5 \mathrm{sec}$ for afterimages and over $3 \mathrm{sec}$ for real images.

The data for dominance periods were analyzed in the same manner as were those for predominance durations, i.e., combining all the levels of rivalry in the first and second $30 \mathrm{sec}$ within one factor. The overall effect for afterimages yielded significance $[F(15,45)=6.48, p<.001]$. Post hoc comparisons indicated that this was accounted for mainly by the difference between the dominance periods in the first and second 30 -sec intervals $(\mathrm{p}<.001)$. The overall mean dominance period for the first $30 \mathrm{sec}$ was $4.08 \mathrm{sec}$, whereas that for the second $30 \mathrm{sec}$ was $6.40 \mathrm{sec}$. The basis for this increase in dominance periods may be twofold. First, and most probably, the increase might lie in the pattern of monocular visibility of line afterimages. Throughout an inspection period of $60 \mathrm{sec}$, afterimages of single lines go through a sequence of complete and partial visibility and whole disappearance (Atkinson, 1972; Wade, 1972). Consequently, the dominance of an afterimage in one eye may have interacted with the state of the afterimage in the other eye, i.e., whether it would have been in a state of visibility or invisibility. Atkinson (1972) reported that a $1 \times 1 / 4 \mathrm{deg}$ line afterimage disappeared for about $14 \mathrm{sec}$ of $60 \mathrm{sec}$ observation. Since the first $20 \mathrm{sec}$ or so are associated with complete visibility (Wade, 1972), it is likely that most of the disappearances were during the second half of the viewing minute. That is, the period of whole-line disappearance of one afterimage during the later parts of the trial may have led to longer periods of dominance of the other afterimage.

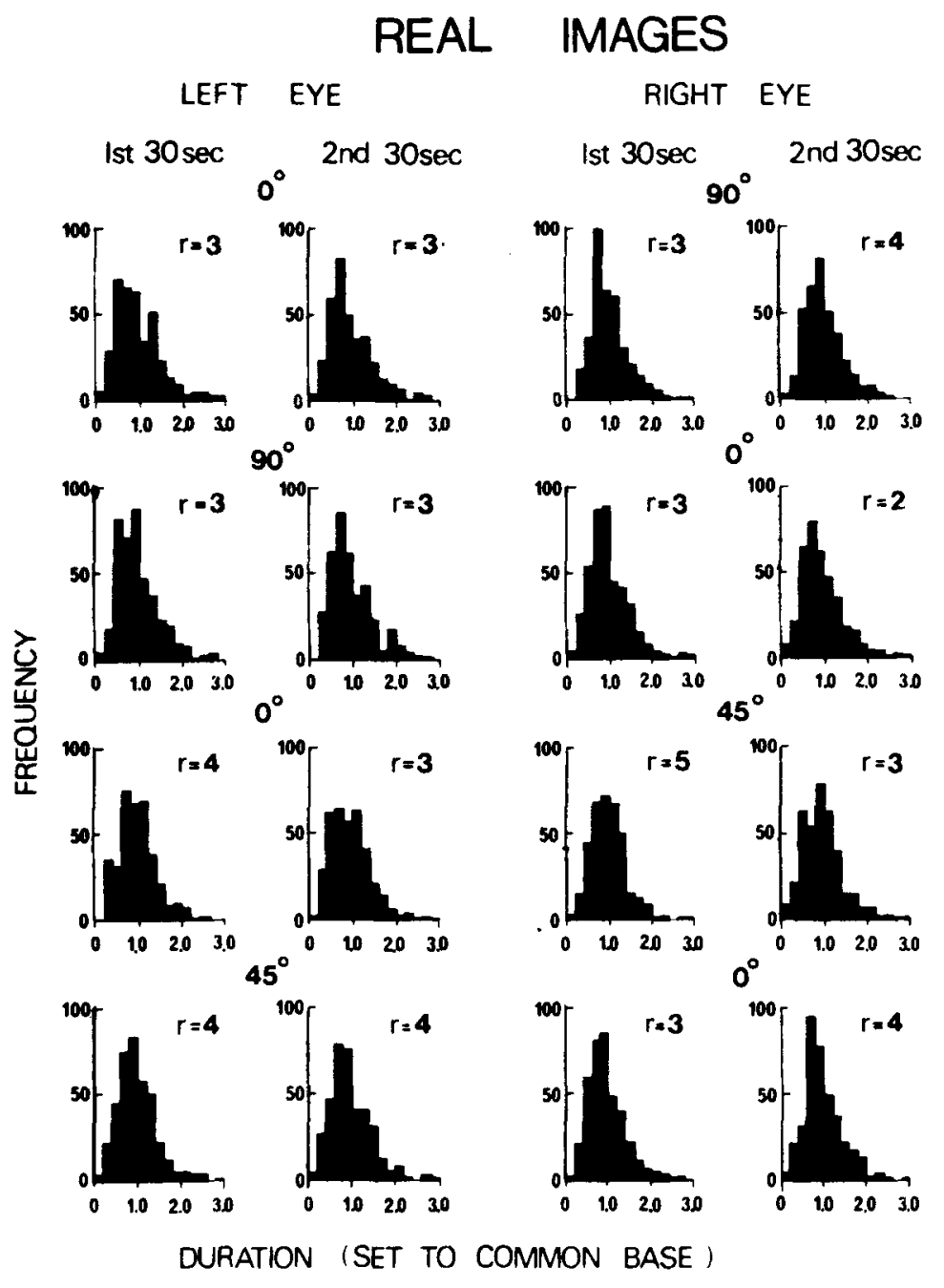

Figure 1. Frequency distributions of dominance periods for real images under all rivalry conditions. The data for each subject were divided by their own mean duration so that the overall mean for all distributions is 1.00. The $I$ values for the gamma distributions are given for each condition. 
However, it should be noted that the durations for which both afterimages disappeared simultaneously (excluding the initial period of invisibility following the flash) did not differ appreciably in the two 30-sec intervals. The second factor concerns the decrease in the apparent intensity of the afterimages throughout the trial. If the apparent intensity of rivalrous afterimages affects the alternation rate in a similar manner to the actual intensity of real images, then the increases in dominance period (and decreases in rate of rivalry) would be expected. It is well established that the rate of rivalry varies as a function of stimulus intensity (Breese, 1899; Kaplan \& Metlay, 1964), being fastest at the highest intensities. One aspect of the data that lends support to this view is that the alternation rate seemed to slow down within the first 10 or $20 \mathrm{sec}$, before the first factor above would have been operating. This aspect was not, however, examined systematically.

The dominance periods for real images retained the same values throughout the observation interval and over rivalry configurations $[\mathrm{F}(15,45)=0.32$, $p>.05]$. Fox and Herrmann (1967) reported a similar result for the alternation rate in ring-disk rivalry over the first and second 30 -sec intervals. The eye-dominance effects mentioned above are mirrored in the data for dominance periods. The periods for vertical lines in the dominant eyes of Subjects 1, 3 . and 4 are longer than those for nonvertical lines in the same eye.

The frequency distributions of the dominance periods were obtained following the procedure used in previous studies (Blake et al., 1971; Fox \& Herrmann, 1967; Levelt, 1968; Wade, 1974). All the dominance periods for a given subject were divided by their mean dominance period for that condition. This results in a common mean of 1.00 for all subjects so that their data could be combined. The frequency distributions, plotted for the first and second $30 \mathrm{sec}$ separately, are given in Figure 1 for real images and in Figure 2 for afterimages. The overall forms of the distributions are similar to those that have been found previously, being positively skewed and conforming to the general characteristics of theoretical gamma distribution. ${ }^{1}$ The $r$ parameter of the gamma function that can be fitted to a distribution is derived for each
Figure 2. Frequency distributions of dominance periods for afterimages under all rivalry conditions, together with the $r$ values.

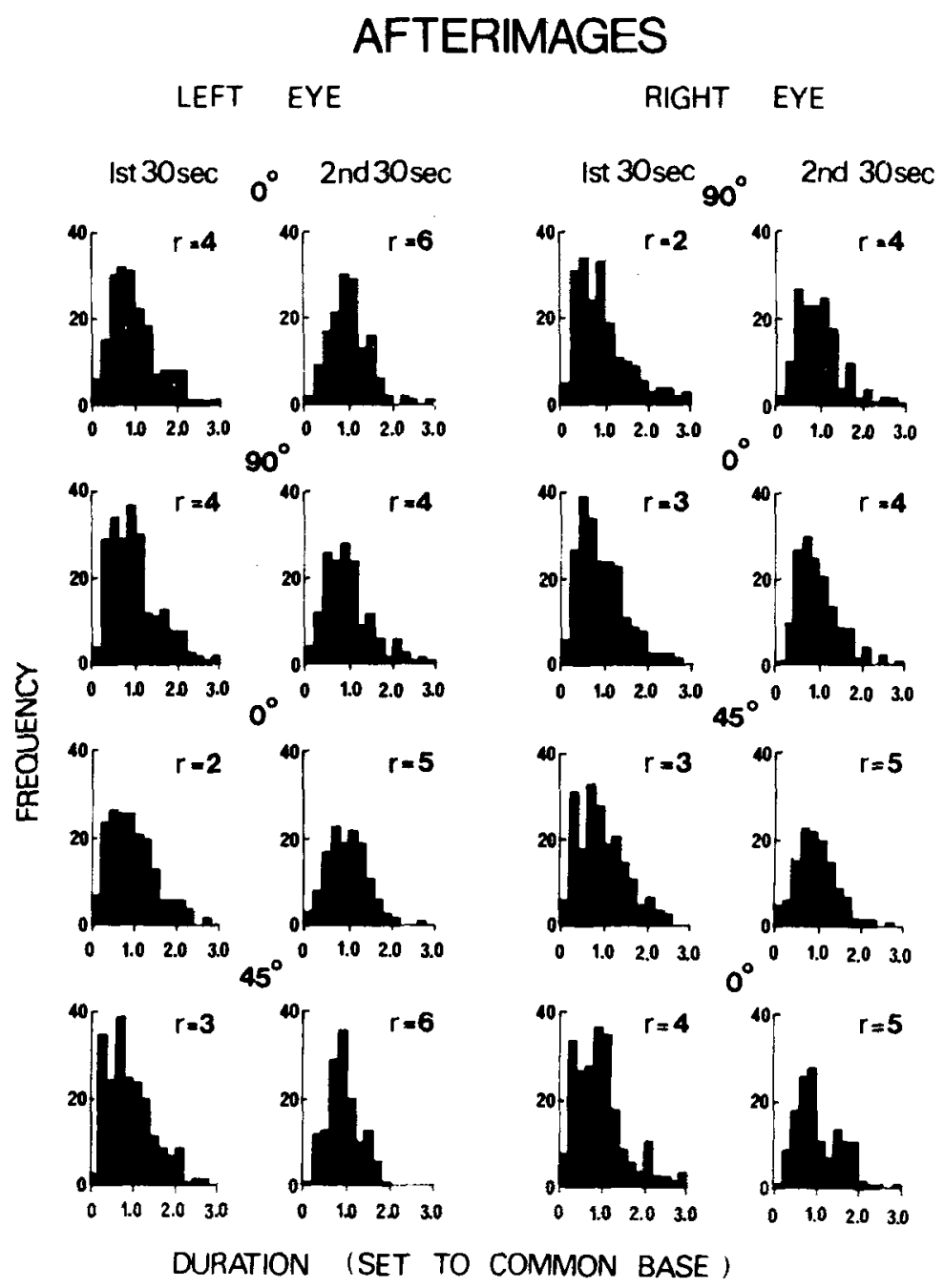


subject as the ratio of the mean squared to the variance of the raw scores (Restle, 1961). The r values, rounded to the nearest integer, are given in Figures 1 and 2 for all the distributions. The interest in determining the value of this parameter is that it can be interpreted as an index of the number of component events comprising a duration (McGill, 1963; Restle. 1961). In the earlier study (Wade, 1974), the $r$ parameter was smaller for rivalrous afterimages than for real images, viewed as gratings. There was little difference between the values in the present experiment: the overall mean values of $r$ were 4.0 for afterimages and 3.4 for real images. This result indicates that under conditions of binocular rivalry alternation, the distribution of dominance periods are similar. Accordingly, the interpretation of this similarity in terms of the components involved in the dominance periods suggest that they are the same for both viewing conditions. The similarity of the frequency distributions, and their approximation to gamma distributions provides evidence for the independence of the rivalry durations under both viewing conditions (Blake et al., 1971; Fox \& Herrmann, 1967).

The above analyses of the frequency distributions did not take into account any order effects between the dominance periods. For example, are successive durations similar to one another or do they differ appreciably? The sequential dependence of successive dominance periods of the lines presented to an eye can be examined using a test devised by Lathrop (1966). It was employed here in the same manner as by Blake et al. (1971) and Fox and Herrmann (1967) for ring-disk rivalry. The test determines the average absolute slope of successive response durations, and its computational formula ${ }^{2}$ is:

$$
L_{j}=\sqrt{\frac{\sum_{i=1}^{N-1}\left|x_{(i+1) j}-x_{i j}\right|}{(N-1) \sigma}}
$$

Table 3

Obtained $L$ Values and $Z$ Scores for the Lathrop Average Absolute Slope Test

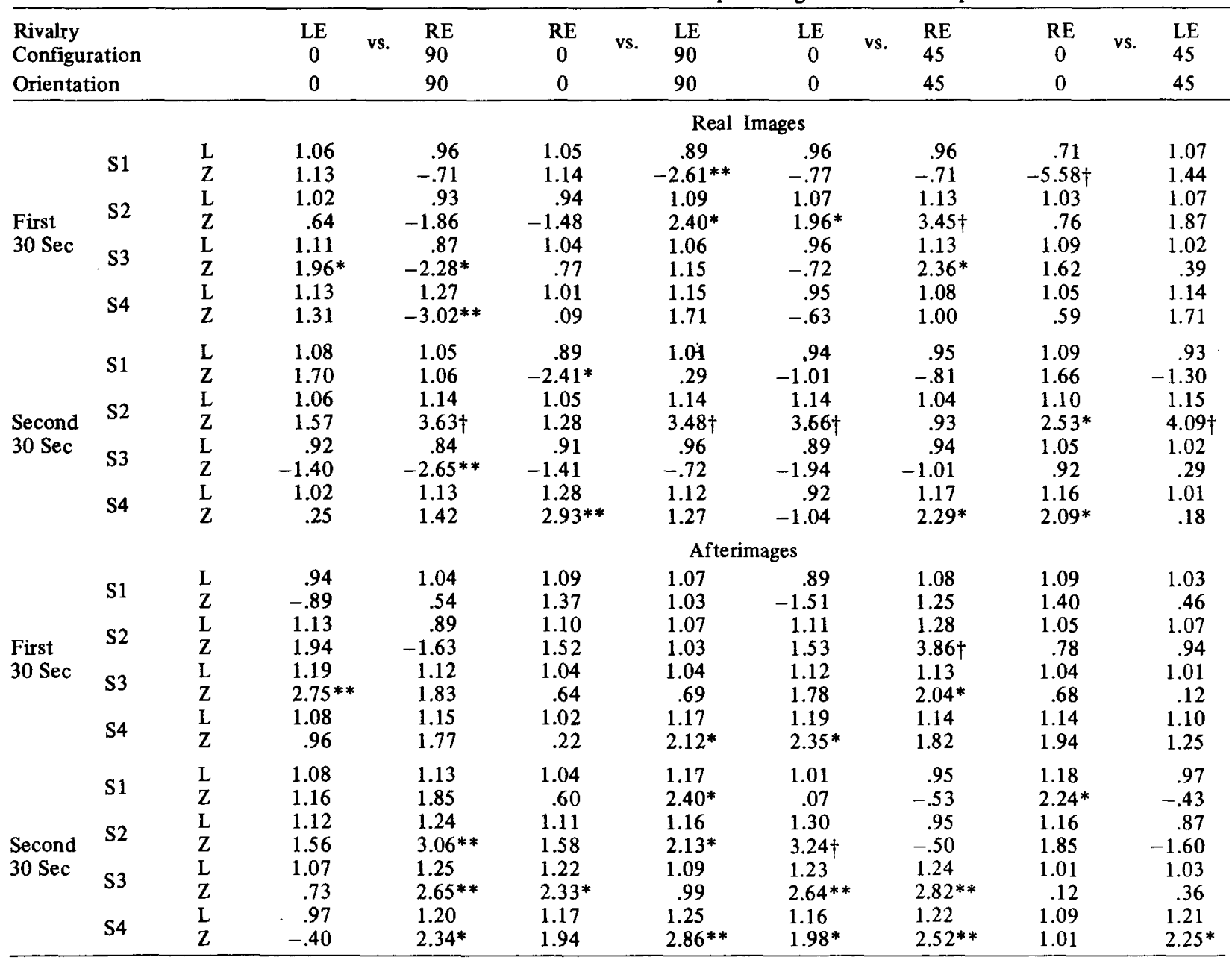


where $L_{j}=$ value of the statistic for the $j$-th sequence

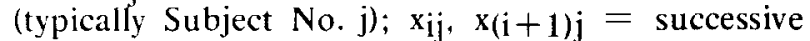
responses in the $j$-th sequence; and $\sigma=$ within $j$ 's standard deviation.

The $\mathrm{L}$ statistic has a value of 1.00 when the successive durations are independent and random, values of less than 1.00 signify a positive relationship between successive durations, and those greater than 1.00 denote a negative relationship. Departures from independence can be determined by deriving $\mathrm{Z}$ scores for the differences between the obtained $L$ values and that expected on the basis of independence (i.e., 1.00). This procedure was followed for the complete sequence of dominance periods for each subject under all rivalry conditions. Both the obtained $L$ values and their associated $Z$ scores are shown in Table 3 . The problems of interpreting so many $Z$ scores are obvious, due to the occurrence of some significant effects by chance alone. Nonetheless, some general observations can be made. In both the real-image and afterimage conditions, 19 of the $64 \mathrm{Z}$ scores are significant beyond the .05 level. All the significant $Z$ scores for afterimages and 13 of those for real images are associated with $\mathrm{L}$ values of greater than 1.00 . It is clear that the tests do not differentiate between rivalry under the two viewing conditions. Moreover, the significant departures from independence are too small in number to warrant consideration of the successive dominance periods as anything other than independent. In consequence, the results of the Lathrop tests are in agreement with the analysis of the frequency distributions in indicating that successive rivalry durations are independent and of random value. This conclusion applies to contour rivalry between both real images and afterimages, and it is in general agreement with the conclusions of Blake et al. (1971) and Fox and Herrman (1967) for ring-disk rivalry. Thus, the central mechanism involved in binocular rivalry would seem to involve an intrinsically random element.

The results of this experiment can be summarized as follows: (1) Binocular rivalry between single lines is not influenced by their relative orientation. This was the case for both real images and afterimages. (2) Dominance periods were longer for afterimages than for real images. The dominance periods increased in duration throughout the 1-min inspection interval for afterimages, but not for real images. (3) Frequency distributions of dominance periods were positively skewed. and conformed to the shape of the gamma distribution, for all conditions. The parameters of gamma distributions were similar for real images and afterimages. (4) Tests of the sequential dependence of successive dominance periods indicated that they were independent and of random value for all conditions.

\section{REFERENCES}

Atkinson, J. The effect of size, retinal locus, and orientation on the visibility of a single afterimage. Perception \& Psychophysics, 1972, 12, 213-217.

Blake, R. R., Fox, R., \& McIntyre, C. Stochastic properties of stabilized-image binocular rivalry alternations. Journal of Experimental Psychology. 1971, 88, 327-332.

Breese. B. B. On inhibition. Psychological Monographs, 1899. 3. No. 1.

Cogan, R. Distributions of durations of perception in the binocular rivalry of contours. Journal of General Psychology, 1973, 89, 297-304.

Cogan, R., \& Goldstein, A. G. Reporting of fragmentations in the binocular rivalry of contours. American Joumal of Psychology, 1972, 85, 569-584.

Fox, R., \& Herrmann, J. Stochastic properties of binocular rivalry alternations. Perception \& Psychophysics, 1967, 2 , 432.436 .

Kaplan, I. T., \& Metlay, W. Light intensity and binocular rivalry. Journal of Experimental Psychology, 1964, 67, 22-26.

KAUFMAN, L. On the spread of suppression and binocular rivalry. Vision Research, 1963, 3, 401-415.

Lathrop, R. G. First-order response dependencies at differential brightness threshold. Journal of Experimental Psychology, 1906. 72, 120-124.

Levelt, W. J. M. On binocular rivaly. The Hague: Mouton, 1968.

McGilL, W. J. Stochastic latency mechanisms. In R. D. Luce et al. (Eds.), Handbook of mathematical psychology (Vol. 1). New York: Wiley, 1963.

Restle, F, Psychology of judgment and choice. New York: Wiley, 1961.

RoDGER, R. S. Intermediate statistics. Sydney: University Co-operative Bookshop, 1965.

WADE, $N$. J. Orientation effects on line afterimages. Perception \& Psychophysics, 1972, 12, 409-416.

WADE, N. J. Orientation and spatial frequency effects on linear afterimages. Perception \& Psychophysics, 1973. 13. 446-450.

WADE, N. J. The effect of orientation in binocular contour rivalry of real images and afterimages. Perception \& Psychophysics, 1974, 15, 227-232.

\section{NOTES}

1. The gamma distribution is expressed by:

$$
f(x)=\frac{\lambda^{r}}{(r-1) !} x^{r-1} e^{-\lambda x}
$$

For mean durations scaled to $1.00, \mathbf{r}=\lambda$.

2. Following the convention of Blake et al., the symbol $L$ is used rather than $\lambda$ as employed by Lathrop.

(Received for publication March 6, 1974; revision received February 19. 1975.) 